\title{
HUMOR E (DES)CONSTRUÇÃO DE FACE NO SITE DESCICLOPÉDIA: UMA ANÁLISE DO OBJETO DE DISCURSO ANITTA
}

\author{
Mônica Lopes Smiderle de Oliveira ${ }^{1}$ \\ Aline Souza de Lima²
}

\begin{abstract}
Resumo: Este artigo se inscreve no escopo teórico da Linguística de Texto em interface com a Pragmática, e tem por objetivo tratar do fenômeno da recategorização no processo de referenciação, da contribuição desse processo para a produção do humor e sobre a construção, manutenção e quebra da face da cantora Anitta no site Desciclopédia. Dessa forma, buscamos demonstrar que as recategorizações estabelecidas pela junção dos elementos verbais com os imagéticos são responsáveis pelo efeito cômico dado à personagem. Destacamos ainda as recategorizações metafóricas, defendidas por Lima $(2013 ; 2009 ; 2003)$ que se destacam em explicar num maior nível de especificação o fenômeno da recategorização. Esta discussão está respaldada, teoricamente, sobre Texto e Hipertexto por Koch e Travaglia (1991); Genette (1997); Koch (2004); Santaella (2013,2008), Paveau (2017) e Carvalho (2018), na Referenciação, Cavalcante (2015; 2013); Lima (2013; 2009; 2003). Além disso, com o objetivo de contextualizar as funções do humor atribuídas à personagem, adotamos os estudos de Propp (1992) e na Pragmática, Goffman (1981) e Brown e Levinson (1983), dentre outros. Os resultados revelam que a recategorização é o processo responsável pela criação do humor depreciativo na figura da personagem Anitta na página Desciclopédia.
\end{abstract}

Palavras-chave: Referenciação. Humor. Face Social.

\begin{abstract}
This article is in the theoretical scope of Text Linguistics in interface with Pragmatics, mainly deals with the phenomenon of recategorization in referencing processes, the contribution of this process to the production of humor and the construction, maintenance and breaking of the face of singer Anitta, on Desciclopédia website. In this way, we seek to demonstrate that the recategorization process is stablished by the junction of verbal and imaginary elements which are responsible for the comic effect given to the character. We also highlight the metaphorical recategorizations, defended by Lima $(2013 ; 2009 ; 2003)$ that stands out in explaining the recategorization phenomenon at a higher level of specification. This discussion is supported, theoretically, on studies of Text and Hypertext by Koch and Travaglia (1991); Genette (1997); Koch (2004); Santaella (2013, 2008), Paveau (2017) and Carvalho (2018), in Referencing, Cavalcante (2015; 2013); Lima (2013; 2009; 2003). In addition, in order to contextualize the functions of humor attributed to the character, we adopted the studies by Propp (1992) and in Pragmatics research, Goffman (1981) and Brown and Levinson (1983), among others. The results reveal that the
\end{abstract}

\footnotetext{
${ }^{1}$ Doutora em Estudos Linguísticos. monicasmiderle@yahoo.com.br

2 Mestre em Estudos Linguísticos. alinerj27@yahoo.com.br
} 
recategorization is the process responsible for the creation of the derogatory humor in the figure of the character Anitta in Desciclopédia page.

Keywords: Referencing. Humor. Social face.

\section{Considerações iniciais}

Neste artigo discutimos sobre a interface da Linguística Textual com a Pragmática, com o intuito de compreender como são construídos os objetos de discurso e a (des)construção da face social das personagens no site Desciclopédia. Dessa forma, nossa intenção é entender como a cantora Anitta é categorizada e recategorizada durante as postagens e também demonstraremos como o humor é produzido nesse ambiente virtual.

Para isso, procuramos subsídios nos estudos de Koch (2004, 2005), Cavalcante (2011), Lima e Cavalcante (2015) sobre a definição de como os objetos de discurso são construídos e como se estabelecem. As autoras informam que os objetos de discurso não são dados a priori, mas construídos no e pelo discurso. Assim, os referentes, uma vez instaurados, podem sofrer recategorizações de acordo com o sentido que os interlocutores pretendem demonstrar durante a interação, seja presencial ou virtual.

Já em relação à construção, à preservação e à quebra de face, buscamos a noção de imagem social de Goffman (1981) para demonstrar "o valor social positivo que uma pessoa efetivamente reclama para si mesma através daquilo que os outros presumem ser a linha por ela tomada durante um contato específico" (p.76-77) e recorremos à teoria de Polidez de Brown e Levinson (1983) para compreender as estratégias de polidez positiva - aquelas que mostram a proximidade entre falante e ouvinte - e estratégias de polidez negativa - aquelas que mostram a distância social entre os interlocutores.

E, por fim, utilizamos os conceitos de Propp (1992) para verificar como a produção de humor é realizada nesse ambiente virtual. Notamos que, para esse autor, a comicidade costuma estar associada ao descobrimento dos defeitos, dos segredos e dos manifestos, daquele ou daquilo que suscita o riso. A comicidade decorre de uma contradição entre a forma e o conteúdo, a aparência e a essência. É exatamente esse 
PERcursos Linguísticos • Vitória (ES) •v. 10 •n. 26 • 2020 • ISSN: 2236-2592 •

Dossiê: Linguagem, Comunicação e Cognição •

humor do descobrimento dos defeitos e do deboche que aparece nas pesquisas do Desciclopédia.

Diante disso, a seguir apresentamos o arcabouço teórico que compõe esse artigo.

\section{Noções de Linguística Textual}

O que é texto? São muitas as possibilidades de resposta para essa questão, pois dependerá da vertente teórica em que se encontra o estudioso. Para Koch e Travaglia (1991) texto é uma unidade linguística concreta que é tomada pelos usuários da língua em uma situação de interação comunicativa específica, como uma unidade de sentido dotada de coesão e coerência preenchendo uma função comunicativa reconhecível e reconhecida independente da sua extensão, em outras palavras texto é o enunciado capaz de transmitir uma mensagem por formar um todo significativo capaz de provocar interação comunicativa.

Entretanto, a noção de texto foi ampliada, devido ao surgimento das redes sociais digitais, nas quais o texto é considerado "plástico", porque se apresenta sob múltiplas significações, seguidas pela intencionalidade e pelas condições sócio discursivas sobre as quais, o texto oriundo dos ambientes virtuais é produzido. A análise desse texto independe de fatores intrínsecos, mas se dá, sobretudo, no contexto.

Além disso, trazemos Koch $(2004$, p.145) ao afirmar que em todo texto há a "existência de uma intertextualidade e/ou polifonia em sentido amplo, constitutiva de todo e qualquer discurso, a par de uma polifonia e de uma intertextualidade stricto sensu, ou seja, todo texto dialoga com outros textos já existentes, pois como afirma Kristeva texto é um mosaico de citações. Koch (2004) explica que a intertextualidade explícita ocorre quando:

É feita menção à fonte do intertexto, como acontece nas citações, referências, menções, resumos, resenhas e traduções, na argumentação por recurso à autoridade, bem como, em se tratando de situações de interação face a face, nas retomadas do texto do parceiro, para encadear sobre ele ou contraditá-lo (KOCH, 2004, p.146). 
Igualmente, o conceito de intertextualidade foi ampliado por Carvalho (2018) que repensou as categorias da intertextualidade, pela luz dos estudos propostos pela LT, com o objetivo de observar os recursos intertextuais existentes nos gêneros imagéticos, já que a conceituação para a intertextualidade foi pensada a partir de textos prototípicos. Baseada no princípio da transtextualidade, defendida por Genette (1997), Carvalho (2018) propõe dividir o que ela classifica de "intertextualidades" em dois grupos: a intertextualidade estrita e a intertextualidade ampla. Desse modo, a intertextualidade estrita diz respeito à relação de copresença ou transformação/derivação de um texto ou de parte dele que podem ser reconhecidas facilmente; enquanto a intertextualidade ampla é caracterizada por alusões menos percebidas a um conjunto de textos, como explicado pela autora:

i) estritas, dadas pela inserção efetiva de parte(s) de um texto em outro ou pela transformação/derivação de um texto específico ou de partes dele em outro texto e ii) amplas, dadas pela retomada não de um texto específico em outro, mas por uma marcação menos facilmente apreensível, porque mais difusa e relativa a conjuntos de textos, verificada por indícios atinentes à forma composicional de um padrão de gênero; ao estilo de um autor deduzido de vários de seus textos ou a uma temática particular divulgada por diversos textos (CARVALHO, 2018, p. 81).

Assim, o site Desciclopédia faz uso da intertextualidade estrita, no sentido de se aproximar do site Wikipédia, pois ativa a função original ao realizar buscas sobre personalidades, locais e eventos, porém o resultado das pesquisas feitas no Desciclopédia sempre estão vinculadas ao humor. Podemos perceber a semelhança entre os dois sites em seus layouts, ou seja, o site Wikipédia é o texto-fonte do Desciclopédia como indicado na imagem a seguir:

Figura 1: layouts

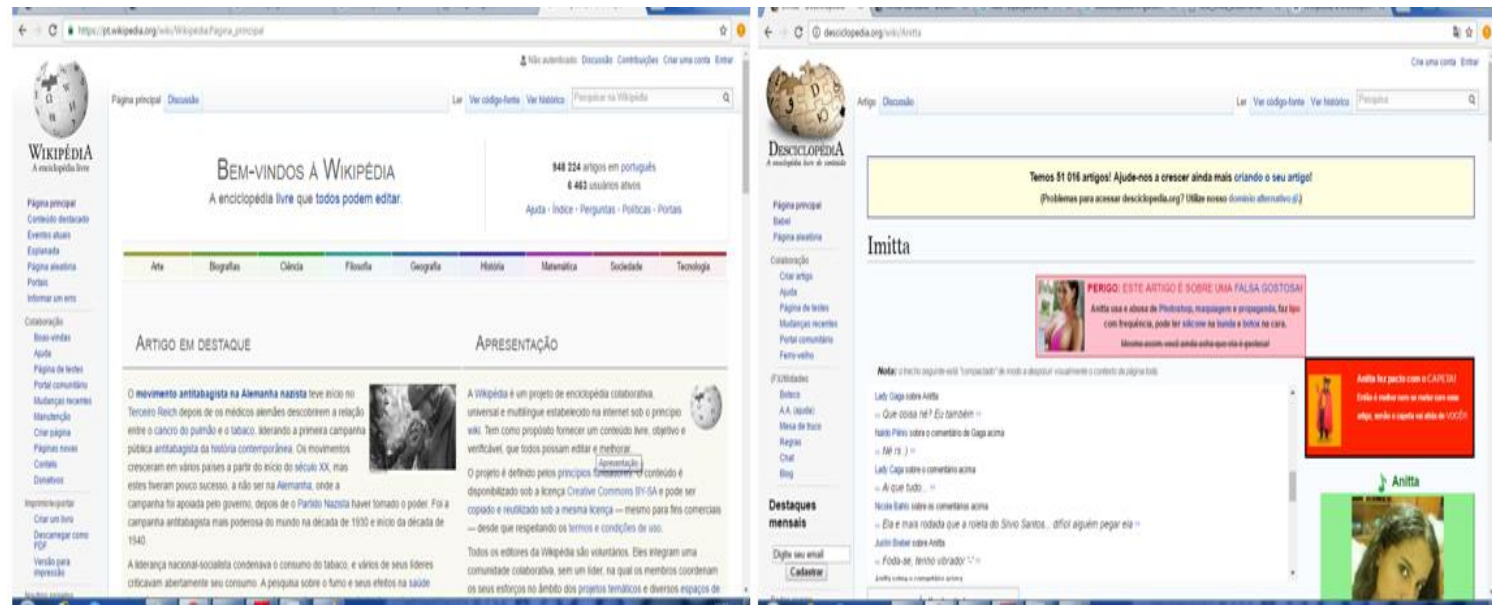


Fonte: site Descicoplédia (2020).

De acordo com as imagens destacadas é possível perceber que o nível da linguagem é diferente, pois no Wikipédia a linguagem é formal, já que se trata de um site de pesquisas, enquanto que no Desciclopédia encontramos uma linguagem irônica, debochada e humorística e isso influencia na recategorização dos personagens pesquisados, pois os objetos de discurso são construídos a fim de produzir crítica e humor.

Não podemos deixar de mencionar que ambos os sites são compostos por hiperlinks, característica presente nos textos de ambiente de hipermídia, que possibilitam uma leitura não- linear, como afirma Santaella (2008)

\begin{abstract}
(...) o texto passou por transformações, por uma verdadeira mudança de natureza na forma do hipertexto, isto é, de vínculos não-lineares entre fragmentos textuais associativos, interligados por conexões conceituais (campos), indicativas (chaves) ou por metáforas visuais (ícones) que remetem, ao clicar de um botão, de um percurso de leitura a outro, em qualquer ponto de informação ou para diversas mensagens, em cascatas simultâneas e interconectadas (SANTAELLA, 2008, p. 47).
\end{abstract}

A noção de hipertexto e a não-linearidade referem-se, de acordo com a autora, aos multimeios, às misturas e aos sons, aos ruídos, às imagens de todos os tipos, fixas e animadas. Todo esse complexo sistema de informação redundou ainda em um ambiente vasto denominado hipermídia. Santaella (2008) aponta, inicialmente, que para compreender o hipertexto é preciso atentar para o processo de digitalização das informações (uma grandeza física) que consiste em:

(...) dividir essa grandeza em pequenas frações, mediante seu valor em intervalos regulares (para a música de um compact disc, 40.000 vezes por segundo). Em seguida, é necessário quantificar esse valor, atribuindo-lhe um código informático sob forma binária, isto é, utilizando apenas dois números, 0 e 1(bits da informação). O sinal digital traduz-se assim por um fluxo de bits estocado em um disco laser e agrupado em pacotes, sendo suscetível de ser tratado por qualquer computador (SANTAELLA, 2008 p. 49).

A autora apresenta quatro traços que definem o hipertexto: a topologia, a multilinearidade, a reticularidade e a manipulação. Sendo que a topologia diz respeito à manutenção do sistema, independente das ações que ele possa sofrer. Existe uma 
ausência de limites ou partes bem-definidas. Já a multilinearidade acontece pela interconexão de suas partes (os nós). Nessa perspectiva, cabe ao leitor/usuário traçar seu percurso de navegação. A reticularidade refere-se ao diagrama do hipertexto. Em tal estrutura, não existe início, meio e fim. Desta maneira, os leitores/usuários podem analisar o conteúdo por diferentes pontos de vista e níveis. Como pode ser notado a seguir:

Figura 2: diagrama do hipertexto

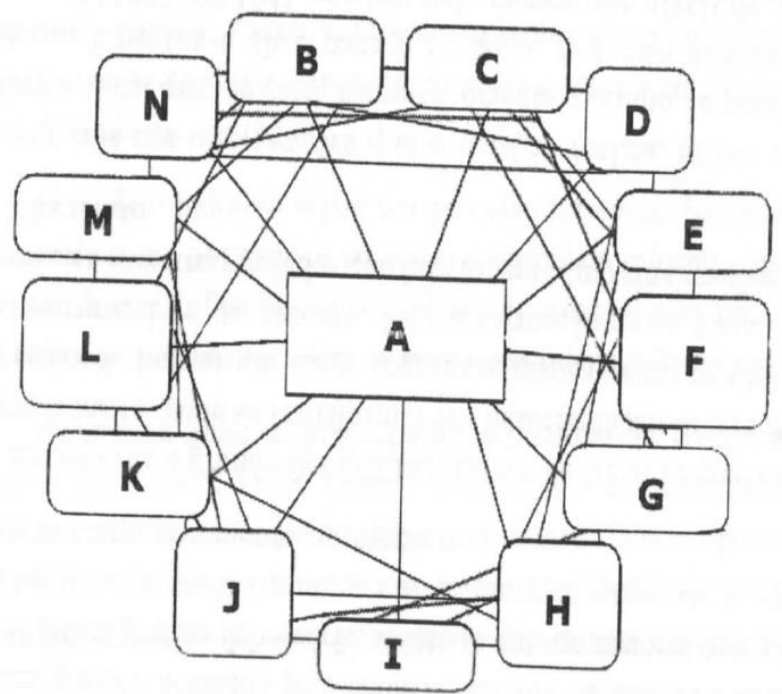

Fonte: SANTAELLA (2008).

Em relação à manipulação ocorre se o leitor/usuário puder interferir ou manipular o suporte em que está sendo visualizado o hipertexto. Dessa forma, todas essas características só podem existir se funcionarem em um suporte hiperespacial que ofereça acesso e mecanismos de inserção de dados por parte do leitor/usuário.

É preciso aludir que segundo a autora o texto aponta três perfis de internautas: o navegador ou internauta errante, internauta detetive e internauta previdente. Navegador errante é aquele que desconhecendo os territórios digitais se aventura pela internet através da intuição. O segundo, o internauta detetive, avança em relação ao primeiro, pois conhece os caminhos pelos quais irá navegar, mas é previsível e evita correr riscos. $\mathrm{O}$ internauta previdente, tendo grande familiaridade com as hipermídias e os ciberespaços, se movimenta com tranquilidade e avança conforme "a lógica da previsibilidade." 
Contudo, cinco anos depois, Santaella (2013) reconhece a emergência dos dispositivos móveis e, consequentemente, a mudança de perfil do usuário/leitor diante dessa nova realidade. Assim, a autora nomeia esse leitor de "leitor ubíquo" no qual, este usuário/leitor passa a ser um cocriador de mensagens, alguém que se constrói no curso da interação.

Paveau (2017) avança nas reflexões sobre os estudos do hipertexto ao ressaltar que no "tecnodiscurso", advindo do surgimento da Web 2.0, tomamos o lugar de "escritoleitores" no qual temos o poder e a autonomia de decidir no que clicar, onde clicar e o que escrever nas hiperligações presentes nesses textos, ação que faz com que nos tornemos tanto leitores quanto escritores autônomos desses hipertextos. E a partir dessas mudanças veremos como podemos referenciar e recategorizar os objetos de discurso.

\section{Conceito de referenciação e objetos de discurso}

Toda prática da linguagem se organiza em conformidade com o gênero textual e a escolha é determinada em função da especificidade de uma dada esfera de comunicação verbal e das necessidades sócio-comunicativas. Assim, cada esfera de atividade social, devido a sua função sócio-ideológica, formulada pela interação verbal de determinados gêneros que permitem nossa comunicação e ação no mundo.

É interessante ressaltar que o sentido é uma construção que depende da interação do leitor com autor e com o texto, pois o sentido não é fixo, nem depende exclusivamente do leitor, mas é uma construção, pois:

Longe de ser uma mera atividade mecânica de decodificação de signos gráficos e de extração de informações, a leitura constitui-se num processo interativo de construção e de negociação de sentidos. Conceber a leitura dessa forma implica entender que o sentido é uma construção que depende da interação do leitor com o autor e texto, atividade que demanda a mobilização de variados sistemas de conhecimento. Nessa acepção, o sentido não é fixo, preestabelecido, uma propriedade do texto, nem depende exclusivamente do leitor, mas é uma construção que tem como ponto de partida a materialidade textual, em suas dimensões verbal e não verbal, e o que ela revela sobre a intencionalidade do autor que este pressupõe como conhecimento compartilhado com o leitor, razão que explica as muitas lacunas contidas no texto (LINS, ELIAS E CAPISTRANO JR, 2013, p. 2). 
Assim, o sentido de um texto é reconstruído na e pela interação e envolve ações conjuntas coordenadas e orientadas para terminar para um determinado fim e que todo o texto contém uma gama de informações somente detectadas quando se tem como pano de fundo o contexto no momento da interação.

A referenciação textual é uma atividade dinâmica que desencadeia intersubjetivamente a construção e reconstrução de referentes. Podemos destacar que as contribuições de Koch que salienta que esta atividade pode ocorrer por meio das seguintes operações básicas: construção/ativação; reconstrução/reativação e desfocalização/desativação. Observemos como ocorrem essas operações básicas:

Tabela 1 - Operações

\begin{tabular}{|c|c|c|}
\hline $\begin{array}{l}\text { 1. Construção/ } \\
\text { ativação }\end{array}$ & $\begin{array}{l}2 . \\
\text { Reconstrução/reativação }\end{array}$ & $\begin{array}{l}3 . \\
\text { Desfocalização/desativação: }\end{array}$ \\
\hline $\begin{array}{l}\text { O "objeto" textual } \\
\text { até então não } \\
\text { mencionado é } \\
\text { introduzido, } \\
\text { passando } \\
\text { preencher um } \\
\text { nódulo (“endereço" } \\
\text { cognitivo, locação) } \\
\text { na rede conceitual } \\
\text { do modelo de } \\
\text { mundo textual: a } \\
\text { expressão } \\
\text { linguística que o } \\
\text { representa é posta } \\
\text { em foco na } \\
\text { memória } \\
\text { trabalho, de tal } \\
\text { forma que esse }\end{array}$ & $\begin{array}{l}\text { Operação pela qual um } \\
\text { nódulo já presente na } \\
\text { memória discursiva é } \\
\text { reintroduzido na memória } \\
\text { operacional, por meio de } \\
\text { uma forma referencial, de } \\
\text { modo que o objeto de } \\
\text { discurso permanece saliente } \\
\text { (o nódulo continua em } \\
\text { foco). }\end{array}$ & $\begin{array}{l}\text { Ocorre quando um novo } \\
\text { objeto-de-discurso } \\
\text { introduzido, passando a ocupar } \\
\text { a posição focal. O objeto } \\
\text { retirado de foco, contudo, } \\
\text { permanece em estado de } \\
\text { ativação parcial (stand by), } \\
\text { podendo voltar à posição focal } \\
\text { a qualquer momento; ou seja, } \\
\text { ele continua disponível para } \\
\text { utilização imediata na } \\
\text { memória dos interlocutores. }\end{array}$ \\
\hline
\end{tabular}




\begin{tabular}{|l|r|r|}
\hline "objeto" fica & \\
saliente no modelo & & \\
\hline
\end{tabular}

Fonte: As autoras (2020).

Assim, os referentes são construídos no curso da interação, uma vez introduzidos os referentes no decorrer da interação podem ser desativados, reativadas, modificados possibilitando a progressão referencial. De acordo com os estudos de Cavalcante (2015)

\begin{abstract}
A 'recategorização' é, por definição, uma alteração nas associações entre representações categoriais parcialmente previsíveis, portanto, em nossa visão pública de mundo. A menor ou maior desestabilização da categoria em mudança é o próprio traço, explícito ou implícito, que define a recategorização de um referente, quer tenha ele sido já introduzido no discurso para ser transformado, quer não tenha sido e se recategorize apenas mentalmente, no próprio momento em que o anafórico remete indiretamente à sua âncora (CAVALCANTE, 2015, p. 132).
\end{abstract}

Dessa forma, um mesmo objeto-de-discurso pode ser categorizado e recategorizado em diferentes situações interativas, pois as cadeias referenciais são construídas sob as influências contextuais que circulam e envolvem as ações de linguagem, a fim de cumprir com o propósito comunicativo firmado entre os interlocutores, adequando-se para construir um efeito de sentido satisfatório.

Ressaltamos ainda o trabalho de Lima (2013, 2009, 2003) sobre as recategorizações metafóricas no qual a autora defende que o processo de recategorização não necessariamente ocorre por uma relação explícita entre um item lexical e uma expressão referencial recategorizadora na superfície textual. A reconstrução dos objetos de discurso está sempre condicionada à ativação dos elementos inferidos no plano contextual.

Além disso, a autora destaca que o processo de recategorização não se dá, necessariamente, na linearidade do texto. Lima $(2013,2009,2003)$ afirma que, nesse caso, a transformação dos objetos de discurso vai acontecendo, na medida em que as inúmeras pistas dadas por expressões referenciais ou não, auxiliam o leitor a compor novos sentidos, novo referências. Daí, a razão desse movimento de recategorização ser muito mais complexo daquela que ocorre de forma circular. Ou seja, na 
recategorização que não é linear, é necessário passar pelos vários elementos nos quais, ela se ancora.

Passemos então, para os conceitos da Pragmática.

\section{Noções de Pragmática}

Escandell Vidal (2006[1993]) declara que a linguagem é o meio mais poderoso na relação interpessoal, pois sempre a utilizamos quando pretendemos atingir certos objetivos, cujas consequências dependem diretamente de outras pessoas. A autora acrescenta que - no se trata tan sólo de que el lenguaje sirva de vehículo para las propias intenciones, sino que debe serlo también de una interacción con los demás ${ }^{3}$ (ESCANDELL VIDAL, 2006[1993], p.159).

Assim, nas interações sociais, desenvolvidas pelos grupos sociais, há a necessidade de que os interlocutores possam manter uma relação cordial. Para Leech (1983), a cortesia é uma estratégia para poder manter uma boa relação, pois é destinada a minimizar os conflitos. Leech (2014) declara que a polidez é não obrigatória, uma vez que as pessoas podem ser não polidas: elas normalmente se comportarão educadamente, porém, também podem ser indelicadas, por exemplo, um membro da plateia poderia ter vaiado, assobiado ou sentado em silêncio quando chegou a hora do aplauso. No caso de apresentações de concertos, isso parece ser raro em sociedades de língua inglesa, mesmo quando a performance é ruim - mas não pode ser descartada.

Cabral, Seara e Guaranha (2017) afirmam que a descortesia e a cortesia possuem uma abordagem sociológica que é inspirada nos trabalhos de Goffman (1981) e defendem a dimensão de face e território, com objetivo de preservar a face, na medida em que privilegiam a relação e a consideração pelo outro.

A noção de face foi elaborada por Goffman (1981, p. 76-77) e pode ser definida como "[...] o valor social positivo que uma pessoa efetivamente reclama para si mesma através daquilo que os outros presumem ser a linha por ela tomada durante um contato específico".

\footnotetext{
${ }^{3}$ Não é apenas que a linguagem serve como um veículo para as intenções de alguém, mas também que deve ser uma interação com os outros.
} 
Para ele, face é o conceito atribuído pela sociedade, é uma espécie de máscara, usada para proteção ou ataque, assim seriamos como atores sociais capazes de desenvolver papéis, podendo interpretar quaisquer situações em que tivermos envolvidos. O referido autor acredita que na interação os atores modificam sua face, podendo deixar de atuar um papel social e incorporar outro papel, dependendo da situação em que estão inseridos.

A face social de uma pessoa é o que ela possui de mais pessoal, o centro de sua segurança e prazer, "trata-se de um empréstimo que lhe foi feito pela sociedade: poderá ser retirada caso não se comporte de modo a merecê-la" (Goffman, 1981, p. 81). É uma linha que ela segue perante a sociedade.

Podemos perceber que o termo "face" expressa denotativamente o significado de "dignidade", "autorrespeito" e "prestígio", representando aspectos afetivos e sociocognitivos. Essa duplicidade de sentidos é usada por Goffman ao aplicar a terminologia shame faced $=$ ficar envergonhado; to save face $=$ salvar as aparências $=$ salvar a face e to lose face $=$ perder o prestígio, desacreditar-se $=$ perder a face .

Embasados nessa teoria de face, Brown e Levinson (1983) elaboram a terminologia "face negativa" que corresponde ao território de cada um (seu corpo, sua intimidade) $e$ "face positiva" que está relacionada com a imagem que deseja transmitir aos outros, ou seja, a sua fachada social. Portanto:

Notamos que a face negativa se refere ao desejo de não imposição, enquanto que a face positiva refere-se à fachada social que tentamos manter numa interação. Destarte, a face pode ser mantida, perdida, recuperada. Normalmente, a face de todos depende do esforço e da manutenção da face alheia. Lima (2007) esclarece que não há nada de depreciativo na face negativa: "ela tem esse nome porque é definida em termo de não-limitação da ação do indivíduo" (LIMA, 2007: 69).

Brown e Levinson (1983) declaram que tanto o ouvinte quanto o falante pretendem "manter a face um do outro", pois vivem em grupo e só serão aceitos se respeitarem as regras da sociedade e se quiserem ser aceitos terão que respeitar certas normas sociais. Tendo que manter a face positiva que é a necessária para serem aceitos pelos membros de um mesmo grupo, porque se escolherem a face negativa, que é a necessidade de ter liberdade de ação e não receber ordens; não serão aceitos pelo grupo. 
Mostraremos alguns atos que podem ameaçar a face dos participantes da interação:

1) Atos que podem ameaçar a face negativa do ouvinte (ex.: advertências, avisos pedidos, ameaças,);

2) Atos que podem ameaçar a face negativa do falante (ex.: aceitar um oferecimento, aceitar um agradecimento, prometer relutantemente);

3) Atos que podem ameaçar a face positiva do ouvinte (ex.: desaprovação, críticas, queixas, levantamento de assuntos "tabu") e

4) Atos que podem ameaçar a face positiva do falante (ex.: aceitar elogios, pedidos de desculpa, confessar-se).

Brown e Levinson (1983) afirmam que tanto o falante quanto o ouvinte tendem a "manter a face um do outro", porque vivemos em uma sociedade e se quisermos ser aceitos temos que respeitar certas regras sociais. Temos que manter a face positiva que é a necessidade de ser aceito pelos membros de um mesmo grupo social; porque se escolhermos a face negativa, que é a necessidade de ter liberdade de ação e não receber ordens; não seremos aceitos pelo grupo social.

Para manter a face positiva do seu interlocutor, a fim de se aproximar deste e ganhar aceitação e admiração, Brown e Levinson (1983) listam as estratégias de polidez positiva que visam reduzir a distância social:

1. Demonstre interesse, aprovação e simpatia pelo interlocutor;

2. Intensifique o interesse pelo outro;

3. Adote marcas de identidade de grupo;

4. Considere os interesses, vontades e necessidades do interlocutor;

5. Procure concordância, conciliação;

6. Evite desentendimentos;

7. Inclua o ouvinte na interação;

8. Explicite reciprocidade;

9. Prometa, ofereça coisas;

10. Forneça benefícios ao ouvinte (simpatia, cooperação etc.). (BROWN; LEVINSON, 1983:391).

Já em relação às estratégias de polidez negativa, os autores informam que são usadas com o objetivo de estabelecer um tratamento mais distanciado, evitando, assim, as imposições e invasões às faces dos participantes envolvidos na interação. Assim, como fizeram anteriormente, apresentam as estratégias mais importantes: 
1. Minimizar a imposição;

2. Mostrar respeito;

3. Ser indireto;

4. Desculpar-se;

5. Impessoalizar o discurso, evitando o uso dos pronomes pessoais do caso reto eu e você;

6. Agir como se estivesse em débito com o interlocutor (BROWN; LEVINSON, 1983:392).

Assim, Lins e Capistrano Junior (2017) justificam que a escolha das estratégias de polidez vai depender das variáveis de poder, distância e teor de risco, pois, dependendo do risco de ameaçar a face do falante e/ou ouvinte, o falante opta por uma estratégia argumentativa de polidez: "Se o risco for baixo, o falante poderá realizar o ato diretamente. Se o risco for alto, o falante vai procurar uma estratégia para realizar o ato de modo que a intenção pretendida seja percebida pelo ouvinte através de uma inferência" (LINS; CAPISTRANO JUNIOR, 2017, p. 35).

Observemos como esse conceito de face pode ser aplicado nas teorias de humor.

\section{Noções sobre humor}

Propp (1992) cita Aristóteles para explicar o que é o cômico e informa que foi Aristóteles quem considerou o humor como próprio do homem. O cômico é a justaposição do trágico e do sublime. Trágico porque quase sempre surge num momento em que algo de inesperado acontece, como uma queda, por exemplo, e sublime porque pode surgir no momento de alegria e felicidade. Foi Aristóteles, também, que teria dito que o humor é uma forma de escarnecer do que ou de quem é considerado baixo, inferior, ou por um defeito físico ou moral, por isso, quando alguém que pertence à elite se veste de uma determinada forma que está fora da moda, às pessoas não acham graça, mas se a mesma roupa for usado por uma pessoa de nível mais baixo, será motivo de chacota.

Convém ressaltar que Propp (1992) parte do pressuposto de que o riso e o cômico não são algo abstrato, pois o homem ri e isso faz parte do comportamento humano. Para definir o riso, cita o teórico e historiador soviético da comédia cinematográfica R. Iurêniev. O riso pode ser alegre ou triste, bom e indignado, 
inteligente e tolo, soberbo e cordial, indulgente e insinuante, depreciativo e tímido, amigável e hostil, irônico e sincero, sarcástico e ingênuo, terno e grosseiro, significativo e gratuito, triunfante e justificativo, despudorado, e embaraçado. Pode-se ainda aumentar esta lista: divertido, melancólico, nervoso, histérico, gozador, fisiológico, animalesco. (R. Iurêniev, apud Propp 1992:50). Assim, podem-se citar seis tipos de riso: o riso que zomba, o riso bom, o riso maldoso, o riso alegre, o riso ritual e o riso imoderado ou desenfreado.

O primeiro é o riso de zombaria, que está ligado à sátira e é o que mais se encontra na vida. A figura do homem, suas ideias, suas aspirações são satirizadas de modos diferentes, por culturas diferentes, épocas diferentes, pois cada povo possui seu próprio e especifico sentido de crítica e de humor, que às vezes não é compreendido em outras épocas ou outros povos; pode-se afirmar, então, que o riso é analisado diferentemente de cultura para cultura.

O segundo é o riso bom, que se manifesta das mais diversas formas, como, por exemplo, "a charge amigável", que é feita não para satirizar, mas para mostrar o lado cômico ou diferente de uma situação ou pessoa: é o caso da caricatura, o homem ri do "defeito" do outro, mas não por zombá-lo, mas por bom grado. Outro exemplo de riso bom são as comédias românticas, em que a força do amor leva ao riso, não o riso de zombaria, mas ao riso de felicidade.

Propp (1992) considera que há autores que estudam o riso, como Bergson, que não admitem existir esse riso bom, pois eles acham que o riso está sempre ligado à tragédia ou desgraça, porque quando se faz uma caricatura, está sendo explorado o lado estranho/diferente da pessoa, como a caricatura de alguém que tenha o nariz um pouco maior do que normal e que é transformado em um nariz gigantesco.

O terceiro tipo de riso que pode ser citado é o riso maldoso que é compreendido como oposto do riso bom; os defeitos que eram encobertos pelo riso bom são aumentados, inflados pelo riso maldoso. $\mathrm{O}$ autor diz que desse riso, em geral, riem as pessoas que não acreditam em nenhum impulso nobre, que veem em todo lugar a falsidade e a hipocrisia. Esse riso não está ligado à comicidade, mas sim a antipatia, porque a desgraça dos outros e a infelicidade alheia são os temas desse riso maldoso; por exemplo, quando um doente ou um idoso cai, quando um cego bate em um obstáculo, ou quando se perde uma pessoa amada. 
O quarto tipo de riso se refere ao riso alegre que não tem relação com os defeitos humanos, surge inesperadamente, por qualquer motivo. Por exemplo, quando um bebê nasce e abre os olhos ou ri, faz com que todos que estão ao redor, também, riem, ou quando se ganha um presente ou quando se vê alguém que não se via há muito tempo. Propp afirma que esse é o melhor tipo de riso “o riso sem causa é o melhor riso do mundo".

Este tipo de riso sempre está ligado ao sentimento coletivo que une os homens, bem diferente do que acontece no riso maldoso, que é um riso individual e expressa prazer e triunfo de um único ser que nem sempre corresponde ao instinto moral da coletividade.

O quinto é o riso ritual, que é visto como uma cerimônia indispensável para se viver. Os antigos diziam que o riso eleva a capacidade de vida e as forças vitais, por isso reservavam-se momentos específicos para se rir. Para eles, o riso era a causa do entardecimento da morte.

O sexto tipo de riso é o riso imoderado ou desenfreado, é uma risada desenfreada que não consegue ser controlada, está ligada às classes socioeconômica inferior e é considerado pelas estéticas burguesas como sendo o mais "baixo", é o riso das festas e das diversões populares como o Carnaval da Europa Ocidental, natal, em que as pessoas se entregavam a comidas, bebidas e risos desenfreados.

E, para finalizar, é importante ressaltar que esses tipos de riso citados anteriormente correspondem às categorias estéticas, enquanto há mais dois tipos de risos extraestéticas que são: o riso histérico e o riso provocado pelas cócegas. Porém, esses dois aspectos de riso não podem ser usados como recursos artísticos para se criar o humor, pois são formas involuntárias do riso.

Vejamos a seguir, como ocorrem o processo de referenciação, a (des)construção de face e humor no site Desciclopédia.

\section{Resultados e discussões}

Segundo Koch (2004), o processo de inferenciação se dá com base no conhecimento de mundo (ou saber enciclopédico) e nas práticas sociais compartilhadas. Assim, com ancoragem na informação dada, opera-se a progressão textual através da introdução de informação nova, estabelecendo-se as relações de 
PERcursos Linguísticos • Vitória (ES) •v. 10 •n. 26 • 2020 • ISSN: 2236-2592 •

Dossiê: Linguagem, Comunicação e Cognição •

sentido. Observemos como é necessário esse conhecimento de mundo no quadro a seguir:

Figura 3: busca Anita

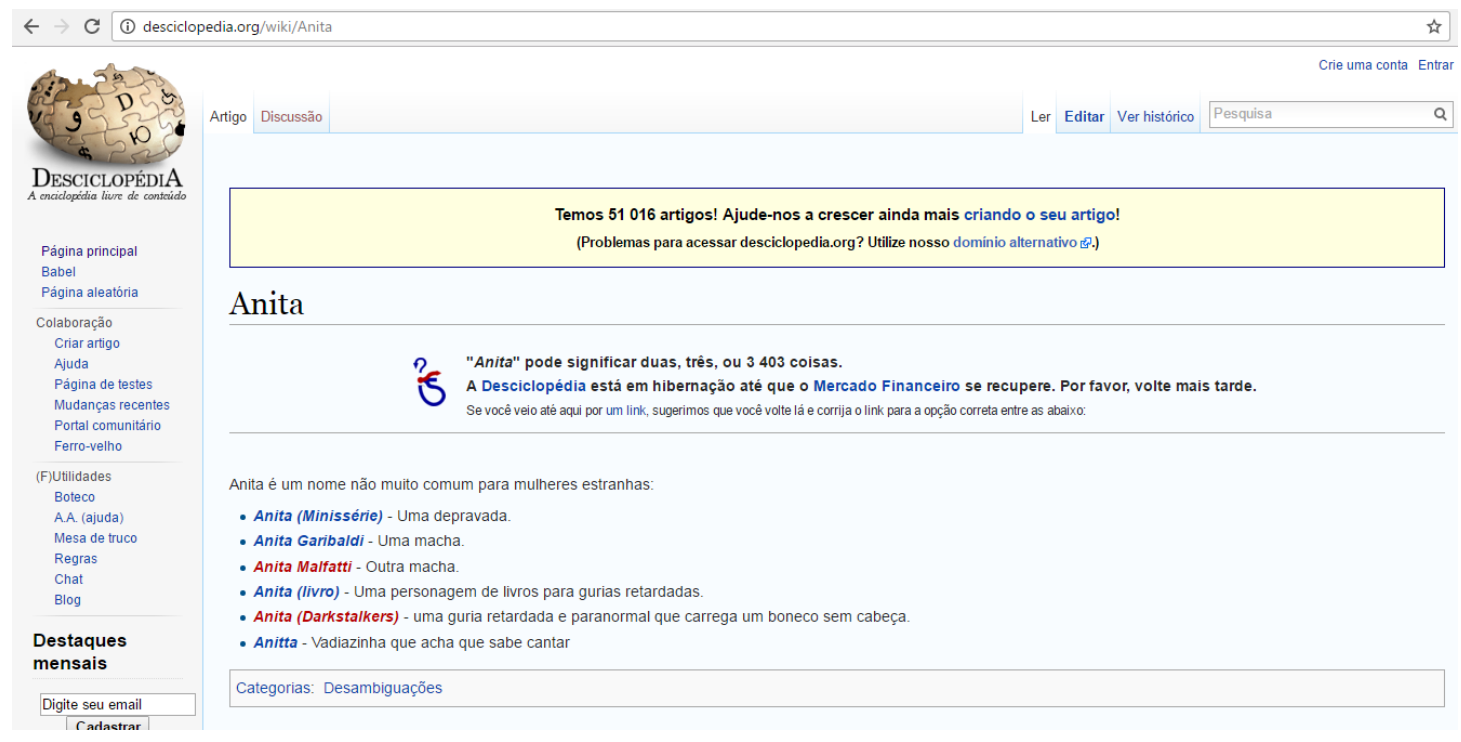

Fonte: site Desciclopédia (2020).

Ao realizar a busca por "Anita" aparecem 6 diferentes personalidades que ativam e remodelam os contextos mentais provenientes a cada uma dessas personagens, pois é preciso observar que segundo Van Dijk (2012) o contexto é construto subjetivo dos participantes, embora apresente componente objetivo, sendo fruto de experiências únicas, originando discursos únicos, por meio de modelo mental que atua no controle da produção e da compreensão do texto e do discurso. Esse(s) modelo(s) mental(is) é/são baseado(s) na(s) experiência(s) interacional(is), podendo ser esquemáticos, apresentando categorias compartilhadas e convencionadas, capazes de controlar a produção e a compreensão do discurso.

Podemos observar que o contexto é formado, ao mesmo tempo, por características pessoais (subjetivas) e sociais (partilha com o grupo), que pode ser atualizado e adaptado constantemente, isto é, o contexto é dinâmico, amplamente planejado, não parte do 'zero' por haver lembranças acumuladas de eventos comunicativos prévios e é imerso em aspectos pragmáticos, pois permite que os usuários adaptem o seu discurso. Dessa forma, ao reativar quem são as "Anitas" presentes na Desciclopédia, remodelamos os conceitos mentais por meio dos conhecimentos prévios e acumulados, como pode ser observado no quadro a seguir: 
Quadro 1: Anitas

\begin{tabular}{|c|c|}
\hline Personalidades & Recategorização \\
\hline 1. Anita (minissérie) & Uma depravada \\
\hline 2. Anita Garibaldi & Uma macha \\
\hline 3. Anita Mafalti & Outra macha \\
\hline 4. Anita (livro) & $\begin{array}{l}\text { Uma personalidade de livros para gurias } \\
\text { retardadas }\end{array}$ \\
\hline 5. Anita (Darkstalker) & $\begin{array}{l}\text { Uma guria retardada e paranormal que } \\
\text { carrega um boneco sem cabeça }\end{array}$ \\
\hline 6. Anitta & Vadiazinha que acha que sabe cantar \\
\hline
\end{tabular}

Fonte: Elaborado pelas autoras (2020).

O quadro revela que na perspectiva interacional, as cadeias referenciais são construídas envolvendo associações e inferenciações para que o sentido seja construído pelos interlocutores, isso pode ser notado nos itens 1, 2, 4 e 5 que fazem uso de sintagmas nominais indefinidos para recategorizar as personalidades. Sendo que em 1, 4 e 5, os objetos de discurso são construídos para mostrar a desvalorização das personagens.

Destacamos a escolha lexical "macha" para recategorizar Anita Garibaldi e Anita Mafalti. A primeira foi companheira do revolucionário Giuseppe Garibaldi, participante ativa da Batalha dos Curitibanos, sendo presa e conseguindo fugir da prisão, já a segunda foi uma famosa artista plástica que inovou e revolucionou suas obras. Essa escolha lexical ativa diretamente o objeto de discurso de mulher que possui iniciativa, que se destaca por executar tarefas que historicamente são destinadas apenas aos homens.

Notamos que no item 6, há o uso da recategorização metafórica que ocorre por meio da forma pejorativa em que a cantora é citada, o uso da anáfora empregada pelo lexema "vadiazinha que acha que sabe cantar" alude a forma como a artista se 
apresenta em seus shows e também alude as letras de suas músicas que exaltam a sexualidade e erotização feminina.

Os atos ameaçadores da face são os que podem afetar a imagem pública de uma pessoa; os atos protetores da face dizem respeito aos atos atenuantes à possível ameaça da face; a face positiva é a necessidade de ser aceito pelos membros de um mesmo grupo social; a face negativa de uma pessoa é a necessidade de ter liberdade de ação e não receber ordens; a face positiva de uma pessoa é a necessidade de ser aceito pelo grupo social e ser tratado como membro desse mesmo grupo. Portanto caracterizamos como atos ameaçadores da face positiva do alocutário o comentário supracitado, pelo fato de afetar o território da cantora. Ao utilizar essa escolha lexical há a ruptura do equilíbrio interacional, prejudicando a autoimagem da Anitta com crítica e insultos.

Compreendemos, então, que, de acordo com o contexto, a interação pode ser considerada como polida ou não, pois, segundo Koike (1989), um ato de fala ou de discurso não é em si próprio cortês ou descortês: dependerá sempre do contexto em que é interpretado e das normas de conduta estabelecidas cultural e socialmente.

Ao clicar no link Anitta - Vadiazinha que acha que sabe cantar, somos direcionados para a seguinte página:

Figura 4: Anitta

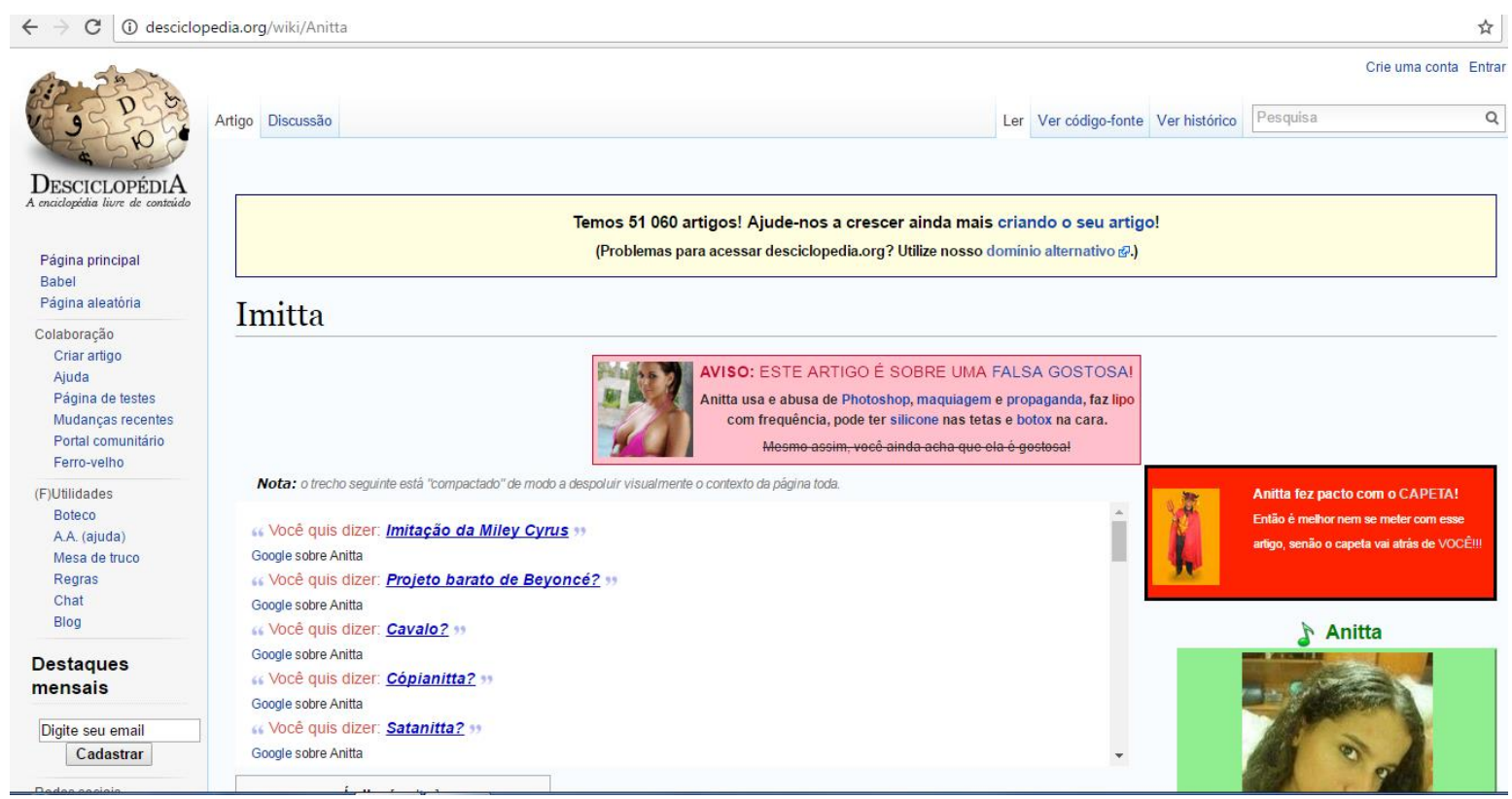

Fonte: Desciclopédia (2020) 
Antes de prosseguir com o resultado da busca, aparece uma sequência de termos que atribuem à cantora uma imagem depreciativa e ruim, destacando assim os atos que podem ameaçar a face da artista, pois reforça o estereótipo de que ela não é original, imitando artistas internacionais como Miley Cyrus e Beyoncé, como pode ser observado nos itens (1), (2), (4) e (8), no quadro 2.

Ao realizar tal ação, verificamos de acordo com Goffman (1985) que em toda interação os participantes podem se sentir ameaçados, embaraçados ou humilhados, visto que na interação é o espaço em que ocorrem os conflitos, as trocas entre os indivíduos. É evidente que os interlocutores se engajam para equilibrar e controlar suas falas de modo que a comunicação ocorra de forma menos ameaçadora possível. Os participantes da interação se envolvem e comunicam algo para alguém, em um determinado tempo e espaço, a fim de estabelecer uma completa e complexa trama que formará o contexto sociointeracional. Neste processo interacional, ocorrem os confrontos que envolvem a imagem social e surgem as noções de face e território, apresentadas por Goffman (1985).

Quadro 2: você quis dizer

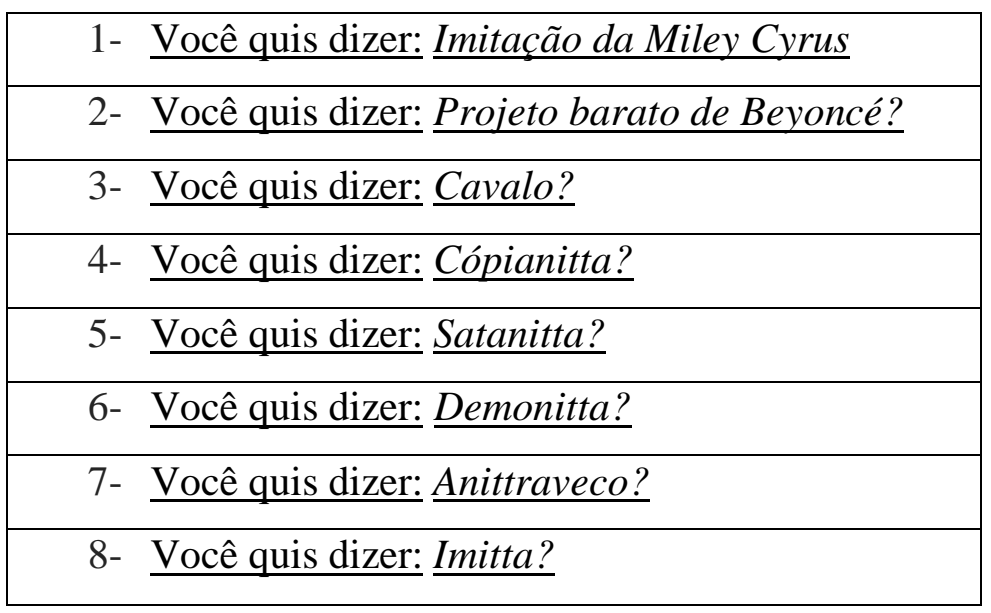

Fonte: Elaborado pelas autoras (2020).

Dessa forma, é importante mostrar as distinções estabelecidas por Goffman (1981) em relação à responsabilidade à ameaça a face. São três tipos: o primeiro, o falante ameaça a face do ouvinte involuntariamente, ou seja, não se da conta que está ofendendo ou sendo grosseiro com o outro, pois se percebesse essa atitude, tentaria 
evitá-la. No segundo tipo, é nítida a intenção de provocar ou insultar. Já o terceiro tipo a ofensa é acidental e o indivíduo sabe dos riscos, mas realiza sem intenção de ferir a face do outro. No site pesquisado podemos perceber que aparece o segundo tipo de ameaça à face, pois é peculiar desse ambiente produzir crítica e humor.

O humor é notado de acordo com o que Propp (1992) desenvolve sobre a ideia de que os diferentes aspectos de riso correspondem aos diferentes tipos de relações humanas, ou seja, o riso está ligado à forma com que tratamos ou julgamos as pessoas; tanto a vida física quanto a vida moral e intelectual do homem podem tornar-se objeto de riso. Para o autor, o riso surge quando existe algo que contradiz o sentido de "certo" que foi imposto, ou seja, o riso nasce da observação de alguns defeitos no mundo em que o homem vive e atua.

Dentre os seis tipos de riso citados por Propp, percebemos que o site Desciclopédia utiliza do riso que zomba, pois esse riso nasce sempre do desmascaramento de defeitos da vida interior, espiritual, do homem. Em muitos casos, esses defeitos são visíveis e não têm necessidade de ser desmascarados, em outros casos ocorre a queda das máscaras e, assim, são mostrados os defeitos do outro; porém o riso só surge quando esse defeito ou outras descobertas semelhantes são inesperadas.

\section{Considerações finais}

Ao longo desse artigo, buscamos responder como são construídos os objetos de discurso e a face social no site Desciclopédia, bem como é produzido o humor nesse ambiente. Assim, o riso produzido proposto pela página é o da zombaria, do escárnio (PROPP, 1992). Ademais, as piadas necessitam para serem entendidas de elementos linguísticos, imagéticos, de inferências e conhecimentos prévios. Identificamos que o site Desciclopédia utiliza o humor como estratégias de polidez positiva (BROWN; LEVINSON, 1987). A estratégia "Seja bem-humorado" é apresentada pelos autores como forma de atenuar uma situação que poderia ser constrangedora.

A respeito da referenciação, entendemos que os elementos linguísticos e não linguísticos presentes na superfície textual (explicitude do texto) não são autossuficientes e nem portadores de sentido completo. Desse modo, concluímos que texto e contexto estão ligados de forma intrínseca. 
PERcursos Linguísticos • Vitória (ES) •v. 10 •n. 26 • 2020 • ISSN: 2236-2592 •

Dossiê: Linguagem, Comunicação e Cognição •

Além disso, os contextos são fundamentais no processo de interação. A imbricação entre o verbal e o imagético atua de forma essencial na introdução, manutenção e recategorização dos objetos de discursos. Sobre a recategorização, reconhecemos bem como Lima $(2013,2009$, 2003) que tal processo não se dá na linearidade do texto apenas. Contribui para que o objeto de discurso Anitta seja sempre recategorizado de maneira depreciativa e essa maneira pejorativa é responsável pela quebra de face e a produção do humor que zomba e critica a caracterização da personagem.

\section{Referências}

BROWN, P. \& LEVINSON, S. Politeness: Some Universals in Language Usage. Cambridge: Cambridge University Press. 1983.

CABRAL, A. L. T.; SEARA, I. R., GUARANHA, M. F. (orgs). Descortesia e Cortesia: expressões culturais. São Paulo: Cortez, 2017.

CARVALHO, A. P. L. de. Sobre intertextualidades estritas e amplas. Tese (doutorado) - Orientador: Profa. Dra. Mônica Magalhães Cavalcante. Universidade Federal do Ceará, Centro de Humanidades, Programa de Pós-Graduação em $\begin{array}{lllll}\text { Linguística, } & \text { Fortaleza } & - & \text { CE. } & 2018 .\end{array}$ Em: $<$ http://www.repositorio.ufc.br/bitstream/riufc/39589/9/2018_tese_aplcarvalho.p df>. Último acesso em: 29 jul. 2020.

CAVALCANTE, M. M. Referenciação: sobre coisas ditas e não ditas. Fortaleza: Edições UFC, 2011.

Referenciação: uma entrevista com Mônica Magalhães Cavalcante. ReVEL, vol. 13, n. 25, 2015.

ESCANDELL VIDAL, M. V. Introducción a la pragmática. Barcelona, Ariel, 2006. 
PERcursos Linguísticos • Vitória (ES) •v. 10 •n. 26 • 2020 • ISSN: 2236-2592 •

Dossiê: Linguagem, Comunicação e Cognição •

FELTES, H. P. M; LIMA, S. M. C. A construção de referentes no texto/discurso: um processo de múltiplas âncoras. In: LIMA, S. M. C; CAVALCANTE, M. M. (Orgs.). Referenciação: teoria e prática. São Paulo: Cortez, 2013, p. 30-58.

GENETTE, G. Palimpsests: literature in the second degree. Trad. Channa Newman; Claude Doubinsky. Lincoln: University of Nebraska Press, 1997. Título original: Palimpsestes: la littérature au second degré.

GOFFMAN, E. A elaboração da face: uma análise dos elementos rituais na interação social. In: FIGUEIRA, S. A. (Org.). Psicanálise e ciências sociais. Rio de Janeiro: Francisco Alves, 1981.

A representação do eu na vida cotidiana. Tradução de Maria Célia Santo Raposo. Petrópolis: Vozes, 1992.

KOCH, I. G. V. \& L. C. TRAVAGLIA (1989) Texto e Coerência. São Paulo: Cortez. KOCH, I. G. V. A produção textual do sentido. In: VALENTE, André (org). Língua, lingüística e literatura. Rio de Janeiro: Ed UERJ, 1991.

Introdução à Linguística Textual. São Paulo: Marins Fontes, 2004.

Referenciação e orientação argumentativa. In : $\mathrm{KOCH}$, Ingedore Grunfeld Villaça;

KOIKE, Dale. A. Requests and the Role of Deixis in Politeness. Journal of Pragmatics, 13(2), 1989. MORATO, Edwiges Maria; BENTES, Anna Christina Bentes. Refereciação e discurso. São Paulo : Contexto, 2005.

LEECH, Geoffrey. Principles of Pragmatics. London: Longman, 1983.

LIMA, S. M. C. Recategorização metafórica e humor: trabalhando a construção de sentidos. 2003. Dissertação (Mestrado em Linguística). - Universidade Federal do Ceará, Fortaleza. 
PERcursos Linguísticos • Vitória (ES) •v. 10 •n. 26 • 2020 • ISSN: 2236-2592 •

Dossiê: Linguagem, Comunicação e Cognição •

LIMA, J. P. de. Pragmática Linguística. Lisboa: Caminho, 2007.

Entre os domínios da metáfora e metonímia: um estudo de processos de recategorização. 2009. Tese (Doutorado em Linguística). - Centro de Humanidades, Universidade Federal do Ceará, Fortaleza.

.CAVALCANTE, M. M. (Orgs.). Referenciação: teoria e prática. São Paulo: Cortez, 2013.

LIMA, S. M. C. de.; CAVALCANTE, Mônica Magalhães. Revisitando os parâmetros do processo de recategorização. ReVEL, vol. 13, n. 25, 2015. [www.revel.inf.br]. Disponível em: http://www.revel.inf.br/files/357d083dd43195695b2541a9bde1b43d.pdf

LINS, M. da P. P. ; ELIAS, V. M. S. CAPISTRANO, R. Leitura e compreensão de tiras de quadrinhos: contribuições da linguística textual para o ensino de língua portuguesa. Escola de Comunicações e Artes - Universidade de São Paulo - 20 a 23.08.2013. Disponível em:

http://www2.eca.usp.br/anais2ajornada/anais2asjornadas/anais/11\%20\%20ARTIGO\%20-

\%20MARIA\%20DA\%20PENHA\%20LINS\%20e\%20VANDA\%20MARIA\%20ELI AS\%20e\%20RIVALDO\%20CAPISTRANO\%20JUNIOR\%20-

\%20HQ\%20E\%20EDUCACAO.pdf

LINS, M. da P. P. . CAPISTRANO, R.. Linguística Textual e Pragmática: uma interface possível. In: CAPISTRANO JÚNIOR, Rivaldo; LINS, Maria da Penha Pereira; ELIAS, Vanda Maria. Linguística Textual: Diálogos Interdisciplinares. São Paulo: Labrador, 2017.

MARCUSCHI, L. A. O barco textual e suas âncoras. In: KOCH, Ingedore Grunfeld Villaça; MORATO, Edwiges Maria; BENTES, Anna Christina Bentes. Refereciação e discurso. São Paulo : Contexto, 2005.. 
PERcursos Linguísticos • Vitória (ES) •v. 10 •n. 26 • 2020 • ISSN: 2236-2592 • Dossiê: Linguagem, Comunicação e Cognição •

PROPP, V. Comicidade e riso. Trad. Aurora Fornoni Bernardini e Homero Freitas de Andrade. São Paulo: Àtica. 1992.

SANTAELLA, L. O novo estatuto do texto nos ambientes de hipermídia. In: SIGNORINI, Inês et al (Org.). [Re]discutir texto, gênero e discurso. São Paulo: Parábola Editorial, 2008. (p. 47-72)

—. Comunicação ubíqua. Repercussões na cultura e na educação. São Paulo: Paulus, 2013.

VAN DIJK, T. A. Discurso e contexto: uma abordagem sociocognitiva. Trad. R. Ilari. São Paulo: Contexto. 2012 